\title{
The Sorbitol Pathway: Effect of Streptozotocin Induced Diabetes and the Feeding of a Sucrose-Rich Diet on Glucose, Sorbitol and Fructose in the Retina, Blood and Liver of Rats
}

\author{
H. Heath and Y. C. Hamlett \\ Dept. of Biochemical Pathology, Univ. College Hospital Medical School, London, England
}

\begin{abstract}
Summary. The sorbitol, fructose and glucose content of the retina, blood and liver from normal and streptozotocin diabetic rats fed either a starch- or sucroserich diet for 15 days has been determined. The sorbitol and fructose level in the retina was much higher than that in either the liver or blood and was significantly increased in diabetes on either diet. Such increases in the sorbitol concentration did not occur in either the liver or the blood during diabetes, and the possibility that the sorbitol pathway can play an important metabolic role in the diabetic retina has been discussed. The feeding of a sucrose- as opposed to a starchrich diet did not significantly alter the concentrations of glucose, sorbitol or fructose in the normal rat retina but caused a marked elevation in the diabetic state.
\end{abstract}

Key words: Streptozotocin-diabetes, sucrose diet, retina, blood, liver, glucose, sorbitol, fructose.

Sucrose is split by the enzymes in the brush border membrane of the gut into glucose and fructose [1]. The resulting ketose is rapidly converted into fructose-1-phosphate in the liver [2] but some passes into the general circulation when animals are maintained on a diet containing $68 \%$ by weight of sucrose [3]. Rats fed a high sucrose diet for up to 12 months have been reported to develop a retinopathy similar to that occurring in human diabetes [4]. It was thought possible that the presence of abnormally high concentrations of fructose in the retina might be responsible for the observed pathological changes. It has been shown in the liver that rapid phosphorylation of fructose caused a derangement in adenine nucleotide metabolism, but such changes do not take place in the retinas of normal and diabetic rats fed a sucrose-rich diet [5].

It is known that the sorbitol-fructose pathway exists in the retina since the levels of sorbitol and fructose have been determined both by gas-chromatographic and enzymic methods in the streptozotocin- diabetic rat retina [6], and the presence of aldose reductase has been established in the bovine retina [7]. The possibility existed that a high dietary intake of sucrose might affect the sorbitol-fructose pathway and it was, therefore, decided to determine the level of sorbitol, as well as that of fructose and glucose, in the retina in both normal and streptozotocin-diabetic rats maintained on diets in which the sole carbohydrate source was either starch or sucrose. The levels of sorbitol found in the retina in this present investigation are considerably higher than those previously reported [6] and are of a similar order to those occurring in neural tissue from diabetic animals [8].

\section{Materials and Methods}

\section{Animals}

32 male Wistar rats $(230 \pm 30 \mathrm{~g})$ were fed ad libitum on synthetic diets containing either sucrose or starch as the sole source of carbohydrate. The composition of these diets has been described previously [9]. The rats were divided into 4 groups of 8 rats. Those from 2 groups were rendered diabetic by the injection (i. v.) of $50 \mathrm{mg}$ streptozotocin $/ \mathrm{kg}$ body weight. The presence of diabetes was established by polyuria, glycosuria, failure to gain weight and terminal blood glucose levels. 1 normal and 1 diabetic group was maintained on each diet for 15 days before sacrifice.

\section{Preparation of Tissue Extracts}

The animals were anaesthetised with Nembutal (i. p. $7.2 \mathrm{mg} / 100 \mathrm{~g}$ body weight). The retinas were dissected in situ, the anterior section and vitreous having been first removed, and homogenised in $0.4 \mathrm{ml} 0.6 \mathrm{~N}$ perchloric acid within $5 \mathrm{sec}$ of severance from blood supply. A portion of liver, approximately $2 \mathrm{~g}$, was excised from the living animal into liquid nitrogen within 1 second, ground to a powder, and extracted with $3.5 \mathrm{vol}$ of $0.6 \mathrm{~N}$ perchloric acid. Blood was collected directly from the beating heart into $0.6 \mathrm{~N}$ per- 
chloric acid. The supernatants from the above extracts were adjusted to $\mathrm{pH} 7.0$ with $3 \mathrm{M}$ potassium carbonate and the potassium perchlorate removed by centrifugation. The extracts were stored for up to 4 weeks at $-20^{\circ} \mathrm{C}$ so that all the determinations of each substance in the same tissue extract could be carried out on the same day under identical conditions.

\section{Analytical Methods}

Sorbitol and fructose were determined fluorimetrically using an EEL fluorimeter, model 244, coupled with a Bryans recorder, model 27000 , at an emission wavelength of $460 \mathrm{~nm}$ with an OX 1 filter. Glucose was determined fluorimetrically in retina, and spectrophotometrically [9] in blood and liver using an SP 700 recording spectrophotometer with a light path of $1 \mathrm{~cm}$. The fluorimetric assays were standardised against known concentrations of glucose, fructose and sorbitol.

\section{Determination of Fructose}

This was based on the methods of Klotzsch and Bergmeyer [10]. $120 \mu \mathrm{l}$ extract, $50 \mu \mathrm{l} 0.3 \mathrm{M}$ triethanolamine buffer $\mathrm{pH} 7.6$ and $10 \mu \mathrm{l}$ of an enzyme mixture containing $3.3 \mathrm{mg} / \mathrm{ml}$ glucose oxidase, Boehringer grade 1 , and $10 \mathrm{mg} / \mathrm{ml}$ catalase, were allowed to react at room temperature for 18 hours in order to oxidise the glucose present in the extracts. After heating in a boiling water bath for $15 \mathrm{~min}$ and centrifuging, $50 \mu 1$ of the mixture was added to a cuvette containing $2 \mathrm{ml} 30 \mathrm{mM}$ triethanolamine buffer $0.4 \mathrm{mM} \mathrm{Mg}^{++} \mathrm{pH} \mathrm{7.6,10 \mu l} 0.1 \mathrm{M}$ ATP, $10 \mu \mathrm{l} 10 \mathrm{mM}$ NADP, $5 \mu \mathrm{l}$ hexokinase $(2 \mathrm{mg} / \mathrm{ml})$ and $5 \mu$ l glucose-6phosphate dehydrogenase $(1 \mathrm{mg} / \mathrm{ml})$. After any residual glucose and glucose-6-phosphate had reacted, $10 \mu \mathrm{l}$ of phosphoglucose isomerase $(0.2 \mathrm{mg} / \mathrm{ml})$ was added and the generated NADPH was measured fluorimetrically at $30^{\circ} \mathrm{C}$.

\section{Determination of Sorbitol}

This was based on the method of Williams-Ashman [11]. $50 \mu \mathrm{l}$ of extract was added to a cuvette containing $2 \mathrm{ml} 0.1 \mathrm{M}$ pyrophosphate buffer $\mathrm{pH} 9.5$ and $50 \mu \mathrm{l} 80$ $\mathrm{mM}$ NAD. The change in fluorescence due to the formation of NADH after the addition of $20 \mu \mathrm{l}$ sorbitol dehydrogenase $(4 \mathrm{mg} / \mathrm{ml})$ was measured at $30^{\circ} \mathrm{C}$.

\section{Determination of Glucose}

This was based on the method of Slein [12]. $50 \mu$ l of retinal extract from normal animals, or $10 \mu \mathrm{l}$ from diabetic animals, was added to a cuvette containing 2 $\mathrm{ml} 30 \mathrm{mM}$ triethanolamine buffer $\mathrm{pH} \mathrm{7.6,10 \mu l}$ NADP $(10 \mathrm{mM}), 10 \mu \mathrm{l}$ ATP $(0.1 \mathrm{M})$ and $10 \mu \mathrm{l}$ glucose-6-phosphate dehydrogenase $(0.25 \mathrm{mg} / \mathrm{ml})$. The change in fluorescence due to the formation of NADPH after the addition of $10 \mu \mathrm{l}$ of hexokinase (1 $\mathrm{mg} / \mathrm{ml}$ ) was measured at $30^{\circ} \mathrm{C}$.

\section{Results}

\section{Sorbitol}

The results of the sorbitol determinations are shown in Fig. 1. Sorbitol levels are noticeably higher in retina than liver or blood, both in the normal and diabetic state.

The Effect of Diabetes. Diabetes caused blood sorbitol to fall by $70 \%$ in rats on the starch diet as well as those on the sucrose diet $(\mathrm{p}<0.001)$. In contrast retinal sorbitol rose with diabetes to a similar value for either group. The rise for the sucrose-fed was more marked $(255 \%)$ than for the starch-fed animal (153\%), due to the former's lower value in the normal state $(\mathrm{p}<$ 0.001 and $\mathrm{p}<0.001$ respectively).

Liver sorbitol did not alter in the starch-fed animal but rose significantly $(\mathrm{p}<0.02)$ in the sucrose-fed animal. The rise was due to the lower value obtained for the sucrose-fed in the normal state, and the resulting sorbitol levels for both diabetic groups were approximately the same.

The Effect of Feeding a Sucrose-Rich as Compared to a Starch-Rich Diet to Normal Animals. The sorbitol content of the blood was decreased by $31 \%(\mathrm{p}<0.01)$ and that of the liver by $81 \%(\mathrm{p}<0.001)$. The concentration of sorbitol found in the retina was much greater than that in the other two tissues and this also was decreased by the feeding of sucrose.

The Effect of Feeding a Sucrose-Rich as Compared to a Starch-Rich Diet to Diabetic Animals. The levels of sorbitol in the liver, retina and blood were not altered significantly by diet in the diabetic state.

\section{Fructose}

The results of the fructose determinations are given in Fig. 2. Fructose levels are noticeably much higher in retina than liver or blood, both in the normal and diabetic state.

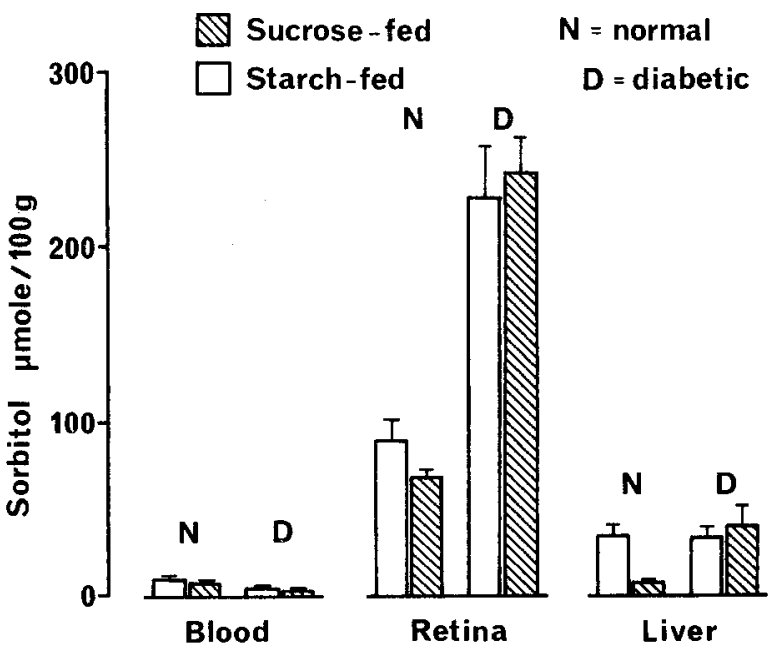

Fig. 1. Sorbitol concentrations of blood, retina and liver from normal and streptozotocin-diabetic rats fed on either a starch- or sucrose-rich diet for 15 days. (Mean \pm SEM for 8 animals in each group) 
The Effect of Diabetes. The liver fructose increased in the starch-fed rats $(41 \%, \mathrm{p}<0.05)$; there was, however, no change in the sucrose-fed rats.

Blood fructose rose considerably with diabetes, $347 \%$ in the starch-fed and $113 \%$ in the sucrose-fed animal ( $p<0.02$ and $p<0.02$ respectively). Levels attained were similar both to each other and to levels in the liver.

Retinal fructose content increased with diabetes by $120 \%$ for the starch-fed group and $203 \%$ for the sucrose-fed group $(\mathrm{p}<0.001$ and $\mathrm{p}<0.001$ respectively).

The Effect of Feeding a Sucrose-Rich as Compared to a Starch-Rich Diet to Normal Animals. Retinal fructose levels were not affected by diet but blood and liver levels rose significantly by $141.5 \%$ and $37 \%$ respectively ( $\mathrm{p}<0.001$ and $\mathrm{p}<0.05$ respectively).

The Effect of Feeding a Sucrose-Rich as Compared to a Starch-Rich Diet to Diabetic Animals. Diet had no effect on the liver or blood but caused an increase of $41 \%$ in retinal fructose $(p<0.02)$. This increase is not mirrored in the normal state.

\section{Glucose}

Glucose concentrations of the blood, retina and liver from normal and diabetic rats fed either on starch- or sucrose-rich diet are shown in Fig. 3. It will be seen that the effect of feeding sucrose to normal rats was to increase the glucose content of the blood $(p<0.02)$ and liver $(p<0.001)$ from 0.73 to 0.91 and from 1.1 to $1.9 \mathrm{mmoles} / 100 \mathrm{~g}$ tissue respectively. However, the glucose content of the retina in the normal animal was unaffected by the feeding of sucrose.

The high levels of glucose in the tissues of the diabetic animals maintained on a starch diet were not further elevated by the feeding of sucrose; in fact a

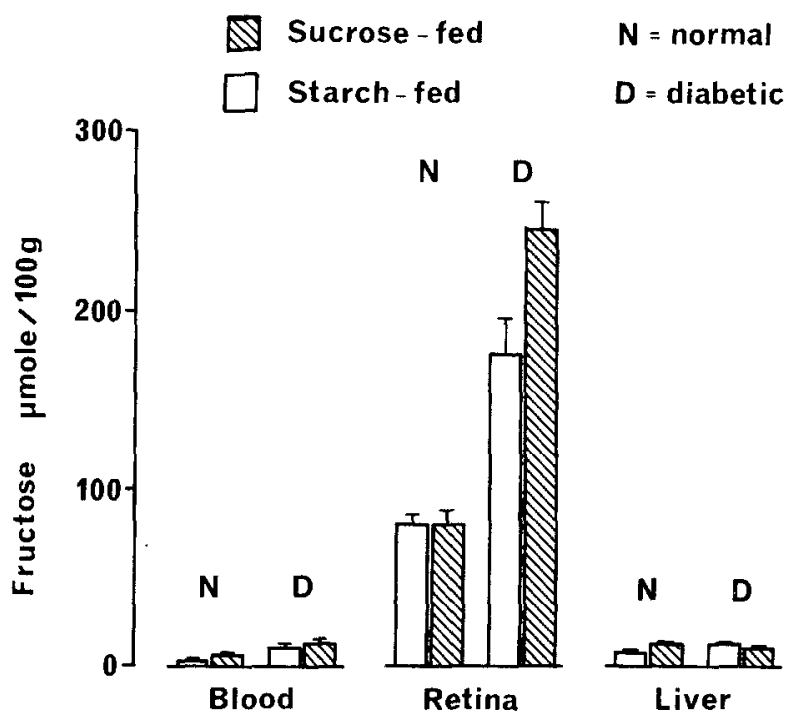

Fig. 2. Fructose concentrations of blood, retina and liver from normal and streptozotocin-diabetic rats fed on either a starch- or sucrose-rich diet for 15 days. (Mean \pm SEM for 8 animals in each group) decrease was observed in the blood and retina. Terminal blood glucose levels were $577 \pm 68.7 \mathrm{mg} / 100 \mathrm{~g}$ for the starch-fed diabetics and $503 \pm 42.8 \mathrm{mg} / 100 \mathrm{~g}$ for the sucrose-fed diabetics. Figures are means of eight \pm SEM

\section{Discussion}

Metabolism in the retina is extremely rapid and in order to study the levels of carbohydrate intermediates it is essential that the retinas be removed from the living animal as quickly as possible. It is not practicable to freeze the whole eye in liquid nitrogen, since it is not possible to dissect the retina in the frozen state. We have developed a technique by which the eyes are dissected in situ in the living animal and the retinal artery is severed at the very end of the dissection, thus enabling the retina to be placed in perchloric acid within 5 seconds. This rapid cessation of metabolism may account for the much higher values we have found for sorbitol and fructose in the retinas of both normal and streptozotocin-diabetic rats than those reported by Hutton et al [6]. These authors analysed the polyol content by gas chromatography, but confirmed their findings with enzymic analysis. They report that sorbitol is the major polyol present in the rat retina, other polyols, which might react with sorbitol dehydrogenase (SDH), being present in negligible amounts.

The high levels of sorbitol found in the retina in the present investigation are in marked contrast to the low values found in blood. The low values of blood sorbitol could not account for the higher mean values of 68.5 and $89,8 \mu$ moles sorbitol/100 $\mathrm{g}$ found in the retina of sucrose- and starch-fed normal animals respectively. It would appear, therefore, that the sor-

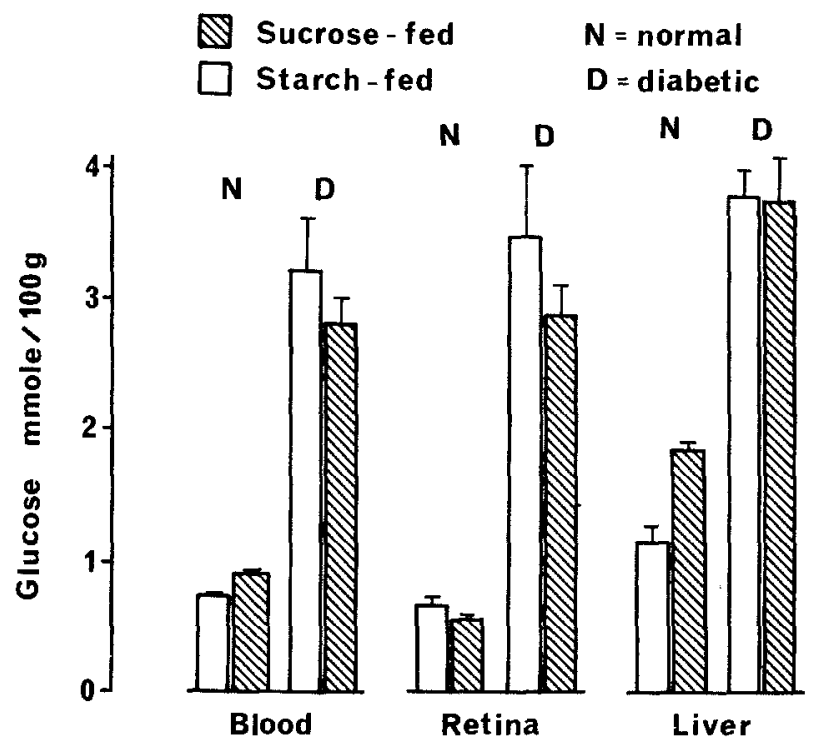

Fig. 3. Glucose concentrations of blood, retina and liver from normal and streptozotocin-diabetic rats fed on either a starch- or sucrose-rich diet for 15 days. (Mean \pm SEM for 8 animals in each group) 
bitol is being synthesised within the retina and not derived from that present in the blood.

The sorbitol pathway is known to take place in the rat lens [13] and in order to confirm that our micro-enzymic method for the determination of sorbitol was not giving erroneously high results, the sorbitol content of the lenses from 2 diabetic rats was determined and found to be $3.5 \mathrm{mmoles} / 100 \mathrm{~g}$ lens which is in agreement with the values of 4.0, 3.1 and 3.0 mmoles/100 $\mathrm{g}$ lens found by Reddy et al. [14], Gabbay and Kinoshita [15] and Hutton et al. [6], respectively.

Sorbitol was not found to accumulate to any marked extent in the liver in diabetes, values of 35.4 and $33.7 \mu$ moles $/ 100 \mathrm{~g}$ being found in the normal and diabetic starch-fed animals respectively.

In the retinas from normal animals, the present studies have revealed that there is a negative correlation $(\mathrm{r}=0.75, \mathrm{p}<0.001)$ between the sorbitol and fructose concentrations, but as the sorbitol concentration increases, as in the diabetic animals, there is an increase in the concentration of fructose which is apparently being generated more rapidly than it can be metabolised, resulting in a positive correlation $(\mathrm{r}=$ $0.70, p<0.01)$ between the concentrations of sorbitol and fructose.

One of the objectives of this investigation was an attempt to find reasons why pathological changes occur in the retina of sucrose-fed normal rats [4]. It would appear from these results that no significant alterations in the glucose, sorbitol or fructose content of the retina occur in sucrose-fed normal animals. However, there is evidence that sucrose-feeding caused an increase of the sorbitol/fructose pathway in the retina in the diabetic state since sorbitol levels rose with diabetes by $255 \%$ for the sucrose-fed group as opposed to only $153 \%$ for the starch-fed animals. There was also an increase in the retinal fructose of $203 \%$ for the sucrose-fed animals against $120 \%$ for the starch-fed animals.

The mean content of $243 \mu$ moles sorbitol $/ 100 \mathrm{~g}$ found in this present investigation in the retina from the sucrose-fed diabetic rats is within the compass of the values for nerve tissue from diabetic animals [16, 8,17 ] but is much lower than that found in the diabetic rat lens $(3,130 \mu$ moles $/ 100 \mathrm{~g})$ [15]. The sorbitol is almost certainly not evenly distributed throughout the retina and, as has been pointed out by Hutton et al. [6], osmotic damage might result if the retinal sorbitol were concentrated to any great extent within certain cells.

Acknowledgements. This research was generously supported by the Clothworkers' Company and the British Foundation for Research into the Prevention of Blindness. The authors are grateful to Miss J R Hodsdon for her cooperation and assistance, to Glaxo Laboratories Ltd. and Roche Products for a generous gift of vitamins and to Upjohn Ltd. who donated the streptozotocin.

\section{References}

1. Gray, G. M., Ingelfinger, F. J.: Intestinal absorption of sucrose in man: interrelation of hydrolysis and monosaccharide product absorption. J. clin. Invest. 45, 388-398 (1966)

2. Woods, H. F., Alberti, K. G. M. M.: Dangers of intravenous fructose. Lancet 1972 II, 1354-1357

3. Bruckdorfer, K. R., Kang, S. S., Khan, I. H., Bourne, A. R., Yudkin, $\mathbf{J}$.: Diurnal changes in the concentrations of plasma lipids, sugars, insulin and corticosterone in rats fed diets containing various carbohydrates. Horm. Metab. Res. 6, 99-106 (1974)

4. Cohen, A. M., Michaelson, I. C., Yanko, L.: Retinopathy in rats with disturbed carbohydrate metabolism following a high sucrose diet. Amer. J. Ophthal. 73, 863-869 (1972)

5. Papachristodoulou, D., Heath, H.: Effect of sucrose feeding and diabetes on adenine nucleotide and phosphate content of rat retina, liver and blood. IRCS Med. Sci. 3, 402 (1975)

6. Hutton, J. C., Schofield, P. J., Williams, J. F., Hollows, F. C.: Sorbitol metabolism in the retina: accumulation of pathway intermediates in streptozotocin induced diabetes in the rat. Aust. J. exp. Biol. med. Sci. 52 (Pt. 2), 361-373 (1974)

7. Gabbay, K. H.: Purification and immunological identification of bovine retinal aldose reductase. Israel J. med. Sci. 8, 1626-1629 (1972)

8. Stewart, M. A., Sherman, W. R., Kurien, M. M., Moonsammy, G. I., Wisgerhof, M.: Polyol accumulations in nervous tissue of rats with experimental diabetes and galactosemia. J. Neurochem. 14, 1057-1066 (1967)

9. Heath, H., Kang, S. S., Philippou, D.: Glucose, glucose-6-phosphate, lactate and pyruvate content of the retina, blood and liver of streptozotocin-diabetic rats fed sucrose- or starch-rich diets. Diabetologia 11, 57-62 (1975)

10. Klotzsch, H., Bergmeyer, H. U.: D-fructose, determination with hexokinase, glucose-6-phosphate dehydrogenase and phosphoglucose isomerase. In: Methods of enzymic analysis (ed. H. U. Bergmeyer), p. 156. New York and London: Academic Press 1963

11. Williams-Ashman, H. G.: D-sorbitol, determination with sorbitol dehydrogenase. In: Methods of enzymic analysis (ed. H. U. Bergmeyer), p. 167. New York and London: Academic Press 1963

12. Slein, M. W.: D-glucose, determination with hexokinase and glucose-6-phosphate dehydrogenase. In: Methods of enzymic analysis (ed. H. U. Bergmeyer), p. 117. New York and London: Academic Press 1963

13. Van Heyningen, R.: Formation of polyols by the lens of the rat with sugar cataract. Nature (Lond.) 184, 194-195 (1959)

14. Reddy, V. N., Chakrapani, B., Steen, D.: Sorbitol pathway in the ciliary body in relation to accumulation of amino acids in the aqueous humor of alloxan diabetic rabbits. Invest. Ophthal. 10, $870-875$ (1971)

15. Gabbay, K. H., Kinoshita, J. H.: Mechanism of development and possible prevention of sugar cataracts. Israel J. med. Sci. 8, 1557-1561 (1972)

16. Gabbay, K. H., Merola, L. O., Field, R. A.: Sorbitol pathway: Presence in nerve and cord with substrate accumulation in diabetes. Science 151, 209-210 (1966)

17. Ward, J. D., Baker, R. W. R., Davies, B. H.: Effect of blood sugar control on the accumulation of sorbitol and fructose in nervous tissues. Díabetes 21, 1173-1178 (1972)

Received: June 9, 1975, and in revised form: October 16, 1975

Dr. H. Heath

Department of Biochemical Pathology

University College Hospital Medical School

University Street

London WC1E 6JJ

England 